\title{
Espacio y ciudad en la teoría situacionista: hacia una crítica del urbanismo
}

\author{
Juan José Navarro Martínez
}

Artículo

Afiliación: Universidad Metropolitana de Ciencias de la Educación (UMCE), Chile.

E-mail: juanj.navarro.m@gmail.com

Recibido: 6 de enero del 2020

Aceptado: 29 de abril del 2020

\begin{abstract}
Resumen
Los miembros de la Internacional Situacionista escribieron sobre diversos temas, siendo este uno de los aspectos que le caracterizaron: la búsqueda de una totalidad. Dentro de aquellos tópicos emergen los relacionados con la arquitectura, el urbanismo y la geografía. El espacio es entendido desde la noción del espectáculo, en donde la mediación de imágenes crea relaciones sociales con fines de acumulación de riqueza. La ciudad no es más que la expresión física de la ideología del urbanismo, un medio presentado a las personas que les es ajeno, que oculta las estructuras que le producen y reproducen. Con un énfasis basado en la recuperación de la vida cotidiana, los situacionistas contrapusieron el urbanismo de los expertos y planificadores, al urbanismo unitario o una reapropiación de la vida como experiencia conjunta a partir de los medios que la humanidad posee.
\end{abstract}

Palabras clave: ciudad; espacio; situacionismo; urbanismo.

Space and city in the situationist theory: towards a critique of urbanism

\begin{abstract}
:
The members of the Situationist International wrote about various topics, this being one of the aspects that characterize them: the search for a totality. Within those emerging topics are related to architecture, urban planning and geography. The space is understood from the notion of the epectacle, where the mediation of images creates social relationships with purposes of accumulation of wealth. The city is nothing more than the physical expression of the ideology of urbanism, a medium presented to the people who alien to them, which hides the structures that produce and reproduce it. With an emphasis based on the recovery of daily life, the situationists countered the urban planning of experts and planners, unitary urban planning or a reappropriation of life as a joint experience based on the means that humanity possesses.
\end{abstract}

Keywords: city; space; situacionism; urbanism.

\section{Juan José Navarro Martínez}

Profesor de Historia, Geografía y Educación

Cívica, Universidad Metropolitana de Ciencias de la Educación (UMCE). Académico del Departamento de Educación Básica, Área Ciencias Sociales, UMCE. Áreas de interés: geografía urbana y rural, geopolítica, producción de naturaleza y conflictos socioambientales. 


\section{Introducción}

I situacionismo, como la teoría emanada de la Internacional Situacionista, fue una postura y una propuesta de praxis enraizada en una crítica de la vida moderna de las ciudades europeas, donde sus dardos apuntaron al aislamiento colectivo, al consumismo, la monotonía y despolitización. En otras palabras, una respuesta frente a una sociedad alienante.

En general, el situacionismo ha sido reducido a una mera tendencia estética y performativa. De ese modo, la Internacional situacionista correspondería a una de tantas vanguardias existentes en el siglo XX como el dadaísmo, surrealismo o existencialismo (Jappe, 1998). De allí, que se considere que sus miembros tendrían una importancia más bien de orden cultural que político. Sin embargo es todo lo contrario, considerando sus principales textos y reflexiones.

El punto de inflexión se encuentra en el aporte teórico que significó desde la Internacional Situacionista en los hechos de mayo-junio existentes durante el año 1968, en medio de una atmósfera de descontento, que previeron de manera bastante precisa la posibilidad de un levantamiento independiente de las condiciones acumulativas de la Francia bajo Gaulle.

Pese a no ser su foco, los miembros de la Internacional Situacionista reflexionaron sobre temáticas como el espacio, las ciudades, el urbanismo, elementos que nos permiten caracterizar dichos conceptos.

El siguiente texto propone profundizar de qué manera sus planteamientos abordan el espacio y la ciudad. En ellos, se encuentra una profunda crítica a una sociedad basada en separaciones. El espectáculo como relación social a partir de imágenes pasa a una reflexión certera en torno al urbanismo. Al mismo tiempo, una estrecha, y no siempre reconocida, relación con Henri Lefebvre.

\section{La Internacional Situacionista}

Previo a que tuvieran una influencia considerable dentro de los círculos estudiantiles, la historia de las andanzas de Debord, quien fuera fundador de la Internacional Letrista, se encontraba anclada a su búsqueda de una vida llena de aventuras. La superación del arte como meta se enarbolaba en bares donde un grupo de jóvenes teorizaba sobre la sociedad que les hastiaba (Jappe, 1998).

La crítica de la separación entre la obra de arte y el espectador será una de las tareas de la primera etapa letrista, cuestión corroborada en la producción cinematográfica de Debord (Jappe, 1998). Para este pequeño grupo, la visión de una obra que se percibe pasivamente es un factor fundamental de un arte entendido como separación de la vida en distintas esferas. De allí, que sus principios y elaboraciones teóricas fueran en una línea marcada hacia solucionar este problema buscando los medios para ello.

Posterior a la disolución del grupo, en 1958 se funda la Internacional Situacionista, impulsada desde las inquietudes de Debord, Vaneigem se integraría al grupo en 1961. Heredera en muchos casos de los postulados letristas, del Surrealismo y de la profunda crítica al arte y la cultura:

"Estamos en contra de la forma convencional de la cultura, incluso en su estado más moderno, pero evidentemente no porque prefiramos la ignorancia, la cordura pequeñoburguesa del carnicero, el neoprimitivismo... Nos situamos del otro lado de la cultura. No antes de ella, sino después. Decimos que hay que realizarla, superándola en cuanto esfera separada." (Internacional Situacionista, 2001, p. 21)

Pero el arte no fue una de las únicas preocupaciones de la Internacional Situacionista. Tanto Debord, como Vaneigem, escribieron acerca de variados temas dentro de sus principales obras. La sociedad del espectáculo (1995), destaca, en el caso del primero, como una obra fundamental para entender la dinámica del capitalismo avanzado, la noción del espectáculo, y ciertas reflexiones en torno a los movimientos revolucionarios históricos. La crítica de la vida cotidiana de Vaneigem, se presentará en su Tratado del 
Saber Vivir Para Uso de las Jóvenes Generaciones (2008).

\section{La crítica de la vida cotidiana y el Espectáculo}

Probablemente, pese que Vaneigem no es presentado generalmente como un autor a considerar dentro de la Internacional Situacionista, siempre eclipsado por Debord, su influencia tiende a ser subterránea. En efecto, muchas de sus frases poblaron las calles de París en medios de los enfrentamientos de mayo y junio del año 1968. Claramente, tuvo la sensibilidad de comprender un contexto y a una juventud que no encontraba satisfecha en las comodidades que ofrecía la sociedad francesa. De allí que postulara que: "No queremos un mundo en que la garantía de no morir de hambre equivalga al riesgo de morir de aburrimiento." (Vaneigem, 2008, p. 18).

Aún más presente en Vaneigem, y su crítica de la vida cotidiana, es el trabajo como actividad alienante, recuperando una tendencia que se encontraba presente en Marx. Recuerda Vaneigem que: "El tripalium es un instrumento de tortura. Labor significa «pena». Existe cierta ligereza cuando se olvida el origen de las palabras «trabajo» y «labor»." (2008, p. 64). Hay cierta atmósfera macabra en el origen etimológico del concepto.

Por otro lado, presenta sus descargos por una sociedad que se encuentra basada en una relación armoniosa entre las personas y el trabajo: "El amor del trabajo bien hecho y el gusto de la promoción en el trabajo son hoy la marca indeleble de la debilidad y de la más estúpida sumisión." (Vaneigem, 2008, p. 65). Es desde estos postulados, que se hace necesaria la superación del estado actual de las cosas.

Debord inicia su conceptualización del espectáculo aludiendo a que en las sociedades actuales todos los aspectos que eran vividos directamente ahora se encuentran en representaciones. Se ha perdido una noción de unidad. El espectáculo representa una unificación, pero no en un sentido de totalidad integrada, sino como separación generalizada (Debord, 1995).

Quizás la mejor definición respecto al espectáculo se encuentra en la tesis cuatro de su libro cuando plantea que: "El espectáculo no es un conjunto de imágenes, sino una relación social entre personas mediatizada por imágenes." (Debord, 1995, p. 9). El espectáculo no es una mera construcción cultural iconográfica, es resultado y producto de un determinado modo de producción, en este caso hegemónico. Su lenguaje es ad hoc a la producción reinante, lo que es al mismo tiempo su propia finalidad.

Para que exista espectáculo, la economía debe existir ya como esfera separada de la vida de las personas, la cual se ha transformado en la esfera desde donde se les somete (Debord, 1995), por lo tanto, la economía capitalista es llevada a sus límites. La separación entre trabajador y producto es al mismo tiempo, una separación entre persona y su propio mundo (Debord, 1995). En la medida en que su vida se ha trasformado en su trabajo, la alienación emerge como forma de separación de la propia vida. Es el desarrollo del capital a tal nivel que este deviene en una imagen.

La teoría de Debord no habría logrado su profundidad ni existencia, en la medida de haber obviado algunas categorías esenciales desarrolladas por Marx en sus escritos económicos. Una de ellas, desde la cual se desprende el espectáculo, es el fetichismo de la mercancía (Marx, 2008). Recordemos que Marx utiliza la noción de fetiche en la medida que a un objeto se le otorgan características humanas. El proceso productivo mediante la separación-unión del obrero y la mercancía provoca que al final solo se observe el producto como objeto, no como trabajo social, ni tiempo utilizado en su elaboración. Es la explotación capitalista que se oculta mediante un dominio subjetivo hacia lo objetivo. En otras palabras, la mercancía esconde la relación social que la produce y recrea, en la medida de que el mundo y sus relaciones sociales se ha construido a partir de ella.

Otro elemento esencial para la conceptualización del espectáculo es la ideología en Marx. La Ideología Alemana (1974), fue el principal texto en donde tanto Marx como Engels intentaron romper con el hegelianismo, así mismo con las visiones materiales de Feuerbach (Marx y Engels, 1974), recién salido a circulación masiva en la década de los treinta del siglo XX. 
La ideología se puede concebir como la idea de un mundo mostrado a la inversa, o el dominio de la falsa conciencia. En efecto, para Marx la sociedad capitalista produce enajenación en la medida que se profundiza el proceso de separación entre el trabajador y el producto de su trabajo (Marx y Engels, 1974). Pero esta separación se encuentra fundamentada en la construcción de la conciencia de un mundo que ha sido construido con base en la existencia de una clase dominante, que es la burguesía. Por lo tanto, a las personas comunes y corrientes se les muestra un mundo determinado, provocando una concientización de acuerdo con sus propios criterios.

La producción de conciencia de las distintas sociedades se relaciona directamente con la producción material (Marx y Engels, 1974). La ideología como inversión del mundo a partir de ideas tiene una cualidad histórica, pese a que se muestra de manera natural. La ideología se provoca allí donde los lazos que unen a las personas bajo un modo de producción aparecen como naturales, no elegibles, una cooperación forzosa (Marx y Engels, 1974). Esa enajenación ignora que aquellos lazos son históricos y que son socialmente producidos, ya que la sociedad tiene dicha capacidad.

En la Ideología Alemana se plantea que el conflicto no es tan solo a nivel material sino con todos los aspectos de la producción de la vida (Marx y Engels, 1974). Al mismo tiempo, las ideas dominantes de una época se establecen como tales en la medida de que una clase posee la capacidad de la dominación material. En ese sentido, la producción espiritual de cada período histórico está relacionado hacia quienes se encuentran controlando la base de reproducción y producción de la vida. Por otro lado, la burguesía establece que sus intereses son de carácter universal (Marx y Engels, 1974), de esa forma toda la sociedad en su conjunto queda bajo sus principios rectores. Por lo tanto, este mundo que se le presenta a las personas nubla su condición histórica en la medida de que se plantea como una condición dada de antemano.

Lo anterior, se relaciona directamente con la frase de Debord al afirmar que: "En el mundo realmente invertido, lo verdadero es un momento de lo falso." (1995, p. 10). El mundo invertido es producido a partir de las relaciones sociales capitalistas, donde lo que se ha considerado verdadero, no es más que un factor de la falsa conciencia existente.

A lo largo del desarrollo capitalista, lo que permite establecer otro elemento fundamental para entender esta nueva versión basada en imágenes es lo sucedido entre el valor de uso y valor de cambio. En un comienzo, con un capitalismo incipiente, aún no industrializado, la valorización del uso tuvo un primer momento, aún no dominante. Fue a través del desarrollo de la sociedad de la mercancía que el valor de cambio tuvo la posibilidad de desprenderse del valor de uso, generándose como factor en sí mismo capaz de elaborar necesidades y consumo masivo (Debord, 1995).

El fenómeno de la alienación se confirma mediante la apariencia de una sociedad que se muestra como distinta. La actitud contemplativa a la que el dominio de la economía por sobre todo los otros aspectos deviene en imágenes, por lo tanto, en espectáculo, en relaciones sociales mediadas por imágenes.

El espectáculo como relación social imperante es un mundo construido a través de mediaciones, es la visión de un mundo objetivada. El espectador es un sujeto alienado, que, mientras más contempla, menos vive, por lo que entre "más acepta reconocerse en las imágenes dominantes de la necesidad, menos comprende su propia existencia y su propio deseo." (Debord, 1995, p. 18). La realidad parcial, fragmentada, presenta la inversión concreta de la vida mediante el dominio y movimiento de lo no-viviente.

\section{Espacio y urbanismo}

El espacio concebido a partir de La Sociedad el Espectáculo puede ser entendido desde lo que Debord establece como el agenciamiento del territorio (Debord, 1995). El territorio, ahora como planeta y espacio mundial ha sido reestructurado para la necesidad de la producción y consumo masivo de mercancías. Una homogeneización global que destruye las barreras y distancias tradicionales. 
Al mismo tiempo, el espectáculo crea el espacio para el consumo, el turismo se ha convertido en una actividad rentable en medida que se integra la esfera del tiempo "libre" del trabajador donde continúa consumiendo imágenes, entonces, este aspecto territorial de la diversión también se constituye como agenciamiento.

Los situacionistas propusieron tres conceptos claves sobre el entendimiento y acción territorial: la deriva, la psicogeografía y el urbanismo unitario.

La deriva es una actitud nueva que se diferencia del paseo, porque busca afrontar el espacio urbano desde una lógica subjetiva, simplemente el perderse dentro de las calles sin un rumbo fijo, se relaciona con el concepto de vagabundear (Internacional Situacionista, 2001). En el fondo, romper con las relaciones rutinarias que entrevén el condicionamiento que el urbanismo y el espectáculo trae a la vida cotidiana.

La Psicogeografía también se relaciona con el concepto anterior en la medida de que pone sobre la mesa las subjetividades de los habitantes de la ciudad. Tanto las emociones como el comportamiento de las personas se relacionan con el medio geográfico en el cual se insertan (Internacional Situacionista, 2001). El mundo actual nos domina, y termina por aplastarnos. Entonces, es crucial poder experimentar a partir de nuevas prácticas las posibilidades de otros espacios posibles.

Estas formas de relación territorial, con el espacio urbano, tienen un fuerte nexo con la geografía humanística y la fenomenología que se desarrollan en su mismo contexto histórico espacial. Tras los grandes conceptos y teorías explicativas de la realidad, el sujeto, está capacitado para reivindicar su propia existencia y su sentir.

El urbanismo es entendido por Debord como la esencia misma de la separación (1995). La ciudad es un espacio en donde convergen dominación, control y poder. Es la integración de individuos separados entre sí, bajo un telón que plantea la unificación como fin. El urbanismo dice ser para todos, pero no permite participación real de quienes viven el espacio urbano. Sin embargo, allí se encuentra también la posibilidad de reintegrar las esferas separadas.

El mantenimiento del orden en la calle acaba terminando con la supresión de esta, del espacio público. La pseudocolectividad en que viven las personas funciona como maquillaje al aislamiento donde el consumo de imágenes se perpetúa. Es el espacio abstracto que construye un territorio en base a su propia necesidad de abstracción como dimensión de la dominación respecto al tipo de vida que se intenta implantar.

El espacio urbano se ha construido con carreteras para los automóviles y grandes centros comerciales para el consumo masivo. La historia de la relación campo-ciudad ha conllevado una dominación de la segunda frente de la primera. La Historia Universal nace desde las ciudades, al igual que la idea de libertad. Pero, el medio urbano también es el medio de la tiranía. Se ha vuelto un espacio de la posibilidad de una vida nueva, mas no de su consumación (Debord, 1995).

El campo se ha vinculado con la idea de aislamiento y separación. El actual urbanismo construye un nuevo pseudo campo, donde un campesinado tecnológico existe a través de la necesidad del control espectacular. Si la dispersión y la falta de conciencia han impedido el protagonismo del campesinado como actor, ahora estos factores se encuentran en el medio urbano (Debord, 1995). La burocracia moderna recrea históricamente la apatía y la ignorancia para crear sus condiciones de dominio exclusivo.

Es entonces que las modificaciones de las condiciones actuales sólo se vinculan con la esfera de la producción, o en términos socialistas la apropiación del trabajo que se roban los capitalistas, sino que son una apropiación de la vida en su sentido profundo: "La revolución proletaria es esta crítica de la geografía humana a través de la cual los individuos y las comunidades deben construir los lugares y los acontecimientos correspondientes a la apropiación no solamente de su trabajo sino de su historia total." (Debord, 1995, p. 108)

Hay dos textos más que proponen tanto la crítica del urbanismo como la conceptualización del urbanismo unitario estos son: El Programa elemental de la oficina del urbanismo unitario escrito por Kolanyi y Vaneigem, y La crítica del Urbanismo escrito por el segundo aparecido en el número 6 de la revista de la Internacional Situacionista. 
El primer elemento para entender es el urbanismo como ideología. Como se plantea:

"El urbanismo no existe: no es más que una "ideología" en el sentido de Marx. La arquitectura existe realmente, como la coca-cola: es una producción investida de ideología que satisface falsamente una falsa necesidad, pero es real. Mientras que el urbanismo es, como la ostentación publicitaria que rodea la coca-cola, pura ideología espectacular. (Internacional Situacionista, 2001, p.15)

El urbanismo se vuelve ideológico en la medida que se presenta ante las personas como espectáculo de la supuesta construcción conjunta de lo que es el medio urbano. ¿Cómo se justifica el urbanismo y su clara tendencia a ser parte del condicionamiento social, del ocultamiento de la necesidad de reedificación para el capital? La respuesta es el cobijo, bajo la necesidad de tener un lugar donde vivir, se fundamenta la construcción de un hábitat que no ha sido producido por las personas, sin la gente y contra la gente. Por tanto, la esfera de la planificación urbana es desenmascarada como una farsa como el dominio de una de una publicidad propagandísticas en la cual las personas realmente no participan del proceso de construcción urbana (Internacional Situacionista, 2001).

El espacio urbano es el espacio privilegiado de la circulación, ya sea de productos o de personas. Es la capacidad de desplazamiento que establece jerarquías al interior de la ciudad. Al mismo tiempo, es el espacio en donde el poder establece sus condicionantes para poder seguir reproduciendo las condiciones de vida existentes. Estas divisiones dentro de la vida en las ciudades es lo que da sentido a la propuesta de urbanismo unitario como construcción de la historia propia.

"La actual planificación de las ciudades, que se presenta como una geología de la mentira, dejará lugar con el urbanismo unitario a una técnica de defensa de las condiciones siempre amenazadas de la libertad cuando los individuos, que no existen aún como tales, construyan libremente su propia historia." (Kotanyi y Vaneigem, 2007, p. 30)

En ese sentido, al entender que el urbanismo reproduce una división que supuestamente integra, mediante la ficción de que las personas son participes del proceso productivo del espacio es la necesidad de una vista hacia una totalidad y la recuperación de todos los aspectos que componen la vida. El devenir ideológico del urbanismo presenta la existencia urbana ya dada, como esfera separada. Lo unitario de un nuevo urbanismo se encuentra en conexión entre dimensiones fragmentadas. Entonces el proceso revolucionario puede definirse como: "...reconstruir integralmente el territorio según las necesidades del poder de los Consejos de trabajadores, de la dictadura antiestatal del proletariado..." (Debord, 1995, p. 108)

El urbanismo unitario pretende la construcción del medio urbano mediante la reapropiación de la vida de parte de las personas. Por lo tanto, el espacio urbano se construirá como ejercicio colectivo utilizando los medios que la humanidad actualmente posee (Kotanyi y Vaneigem, 2007) a diferencia del urbanismo del poder como un uso de las técnicas, pero usadas por expertos y los aparatos represivos, al mismo tiempo que se separa de la idea de quienes dicen hacer urbanismo, pero no construyen el medio de esta disciplina (Internacional Situacionista, 2001).

La idea del urbanismo unitario, como forma de experiencia conjunta implica una construcción de la ciudad que tome en cuenta los deseos y pensamientos de las personas que la habitan. Frente al urbanismo capitalista, se contrapone la posibilidad de otra vida, pero para ello, es fundamental la reapropiación de los medios que dan existencia y reproducen el espacio urbano.

\section{Relación con Henri Lefebvre}

Una de las principales influencias en este aspecto de tanto Debord como Vaneigem, fue Henri Lefebvre. Recordemos que Lefebvre fue un destacado filósofo y sociólogo que escribió decenas de libros en sus años de trayectoria donde destacan temáticas como el marxismo, el espacio, el Estado, y los volúmenes de la Crítica de la vida cotidiana. Pese a provenir de la academia, y haber militado hasta 1958 en el Partido Comunista de Francia, fue uno de los únicos personajes que poseía un rol institucional con quien los situacionistas colaboraron (Molano, 2016). Sin embargo, tras unos buenos primeros años, ya a finales de los sesenta las relaciones colapsaron, acusándose de plagios y presentando críticas cruzadas. 
Lefebvre entiende la vida cotidiana como un campo nuevo, capaz de aportar fructíferamente en la comprensión de los fenómenos sociales. Lo cotidiano es la base de la realidad desde donde se impone una realidad ficticia provocada por la alienación. Vivimos en un mundo de esferas fragmentadas, donde la experiencia se encuentra disgregada en distintos aspectos:

"En lo que concierne a la mayoría de los seres humanos, solo acceden a lo real y lo posible por medio de fragmentos, trabajo monótono, y ningún individuo puede comprender realmente cuál podría ser el significado general y las consecuencias de su trabajo." (Lefebvre, 2014, p. 247)

El deterioro de la vida cotidiana se produce a partir de la técnica, en consiguiente Lefebvre plantea una crítica al trabajo y la alienación económica. Es la relación social del trabajo la que crea una esfera totalmente distinta, abstrayendo la posibilidad de una experiencia integrada. Mientras, por un lado, existen grandes avances tecnológicos, por otro la vida cotidiana se mantiene en un nivel de monotonía constante. Presenta también, una crítica a la socialización de la producción a través del Estado, como un vínculo entre átomos sociales (Lefebvre, 2014), a la vez propone que es la felicidad la forma en que se debe medir el progreso social.

Así, Lefebvre propone la idea del hombre total, desde una concepción que busca la superación de la filosofía. Si Marx planteaba que la filosofía ya había entendido al mundo y ahora se trataba de transformarlo, Lefebvre entendía que, una vez explicada la relación entre las distintas esferas fragmentadas, lo que debía construirse es una experiencia integral, no separada entre todos los ámbitos de la vida. La dominación es un sitio que permite al dominado, pero también su liberación: "El concepto de Lefebvre según el cual lo cotidiano es la frontera entre lo dominado y lo no dominado, en donde nace la alienación, pero también la desalienación, se vuelve a encontrar en la teoría situacionista." (Jappe, 1998, p. 93).

Frente a la pregunta de si la vida cotidiana presenta dentro de su interior mismo las posibilidades de construir una realidad distinta, o en su defecto, es en contra de ella donde nace la vida no fragmentada, Lefebvre tendió a inclinarse en su primer volumen frente a la primera aseveración, en el caso del segundo, hacia la segunda posibilidad. Aquí, emergen las conexiones con las conceptualizaciones situacionistas. Lo cotidiano se ha separado de la historia, quedando a merced del desarrollo de las fuerzas productivas. La tarea consiste en rechazar las esferas que se encuentran por sobre ella, inclusive la política revolucionaria.

En síntesis, en la vida cotidiana se desarrolla la alienación, pero también el espacio donde se puede desarrollar una desalienación. La posibilidad de transformar la realidad encuentra su sentido en la medida en que busca, a través de la experiencia diaria, una reunificación de todas las esferas que se encuentran separadas. La sociedad capitalista solo puede ser abolida en la medida en que sus diversos fragmentos, donde contra la reproducción de la vida, se reencuentren y las personas tengan la capacidad de construir un futuro distinto. Es una superación de la conceptualización economicista del socialismo del siglo XX.

Estas ideas, también se relacionan con la propuesta de Lefebvre del Derecho a la Ciudad (1978). Claramente, tanto Debord como Vaneigem y Lefebvre tuvieron elementos transversales, aunque también diferenciadores. Pese a que hoy en día el Derecho a la ciudad ha tendido más bien a concebirse como una consulta ciudadana frente a los macroprocesos de ideación de cómo administrar el crecimiento urbano, el mercado inmobiliario y la infraestructura pro-capitalista, Lefebvre y, aquí el puente, lo presentó como la reapropiación de los medios de producción de lo urbano por los mismos habitantes de la ciudad.

\section{Elementos finales}

De acuerdo con Barrot (2009), el situacionismo atrae a variadas personas debido a dos elementos claves. El primero es la tendencia desde la Internacional Situacionista a ofrecer una teoría que piensa desde la totalidad. Buscaban darle respuesta a todo 
y ofrecer claves para entender el funcionamiento del mundo. En segundo lugar, la conceptualización usada para caracterizar el capitalismo y los medios de superación presenta tantas ambigüedades que permite que una gran cantidad de tendencias puedan recuperarla.

No podríamos plantear la importancia de la Internacional Situacionista para nuestros días exclusivamente tomando en cuenta sus aciertos. A lo largo de su historia, Debord, Vaneigem y compañía cayeron en una serie de errores que son vitales establecer. Quizás uno de los fundamentales, era considerar que podían escribir y actuar sin equivocarse (Barrot, 2009). La Internacional Situacionista terminó siendo un grupo reducido, siempre tensionado en su interior, de allí la gran cantidad de bajas y purgas, que terminarían con la salida del mismo Vaneigem en 1970.

Pese a los intentos de que la teoría desde la Internacional Situacionista llegara a los grupos obreros, intentando alejarse de los grupos académicos y universitarios, fue en el sector estudiantil en donde consiguieron mayor influencia (Barrot, 2009). De allí, se entiende que su forma poca cercana de escritura no pudiera ser entendida por el proletariado al que incitaban a revelarse.

Ahora, tomando en cuenta sus nociones referentes al urbanismo y la arquitectura, encontramos una noción crítica en torno a la fragmentación de la construcción de la ciudad. La esfera separada de la economía es el motor de otras esferas, donde el urbanismo también entra. Al mismo tiempo, el espacio urbano es ideológico en la medida que se presenta de manera ajena a quienes viven en él. De esa forma la gente existe y actúa, o parafraseando a Zizek, no saben porque lo hacen, pero lo hacen (2003).

Su propuesta de un urbanismo unitario nos recuerda los espacios de representación de Lefebvre (2013) o las horizontalidades y el espacio banal de Milton Santos (1996). En otras palabras, a la construcción de un nuevo espacio, no bajo una lógica acumulativa del valor de cambio. Más bien, una reintegración de lo que ha sido fragmentado. Tomando en cuenta sentires y experiencias de lo común.

Para el situacionismo, el espacio se encuentra moldeado políticamente bajo los imperativos del tiempo mercancía (Velázquez, 2013). Es un espacio de disputa para la construcción de nuevas condiciones de existencia. Su propuesta estético-subjetiva de praxis espacial invita necesariamente a repensar las formas existentes de relación con el entorno. Frente a las necesidades de la circulación de la ciudad moderna y la acumulación de riqueza, la experimentación con la finalidad de construir una nueva vida cotidiana (Bonastra y Jové, 2017).

\section{Referencias Bibliográficas}

Barrot, J. (2009). Crítica de la Internacional Situacionista. Editorial Klinamen.

Benjamin, W. (2008). Obras Libro I/vol. 2. Madrid: Abada Editores.

Bonastra, Q. y Jové, G. (2017). Le Grand Jeu à Venir. Un manifiesto educativo a partir del discurso situacionista sobre lo urbano. Scripta Nova, 21 (573). doi: https://doi. org/10.1344/sn2017.21.17408

Debord, G. (1995). La sociedad el Espectáculo. Santiago de Chile: Ediciones Naufragio.

Internacional Situacionista. (2001). Internacional Situacionista textos completos en castellano de la revista Internationale Situationniste (1958-1969). Vol. 1. La realización del arte Internationale Situationniste \# 1-6. Madrid: Literatura Gris, 2001.

Jappe, A. (1998). Guy Debord. Barcelona: Anagrama.

Kotanyi, A. y V., Raoul. (2007). "Programa elemental de la oficina de urbanismo unitario". En: Urbanismo situacionista (pp. 22-31). Barcelona: Editorial Gustavo Gili.

Lefebvre, H. (2013). La producción del espacio. Madrid: Capitán Swing.

Lefebvre, H. (2014). Critique of everyday life. The one volumen edition. London: Verso, 2014. 
Lefebvre, H. (1978). El Derecho a la Ciudad. Barcelona: Edicions 62.

Marx, K. (2008). El capital. Crítica de la Economía Política. Libro primero el proceso de acumulación de capital I. Ciudad de México.: Siglo XXI Editores.

Marx, K. y Engels, F. (1974). La Ideología Alemana. Crítica de la novísima filosofía aleamana en las personas de sus representantes: Feuerbach, B. Bauer y Stirner y del socialismo alemán en las de sus diferentes profetas. Montevideo: Ediciones Pueblos Unidos.

Santos, M. (1996). De la totalidad al lugar. Barcelona: Oikos-tau.

Vaneigem, R. (2008). Tratado del saber vivir para el uso de las jóvenes generaciones. Barcelona: Anagrama.

Velázquez, A. (2013). Espacio de lucha política: teoría política y el giro espacial. Argumentos (México, D.F.), 26(73), 175-195. Recuperado de http://www.scielo. org.mx/scielo.php?script=sci_arttext\&pid=S0187-57952013000300010\&lng=es\&t lng=es.

Zizek, S. (2003). Ideología. Un mapa de la cuestión. Buenos Aires: Fondo de Cultura Económica. 